\title{
Analisis Korelasi Kawasan Pengembangan Kendal Industrial Park Terhadap Ruang Terbuka Hijau
}

\author{
Yudo Prasetyo*, Nurhadi Bashit, Hanum Fadhil Baihaqi \\ Departemen Teknik Geodesi, Fakultas Teknik, Universitas Diponegoro \\ Jl. Prof. H. Soedharto, SH. Tembalang, Semarang, 50275 Indonesia \\ Email: yudo.prasetyo@ft.undip.ac.id
}

\section{Abstract \\ Correlation Analysis Of Development Kendal Industrial Park With Green Open Space}

The Industrial Park in Indonesia has increased in each province, especially in Central Java Province because it has a positive impact on prosperity, economic level and can open jobs. Kendal Industrial Park (KIP) is one of the Industrial Park in Central Java that is experiencing growth and is expected to attract investors to enter. KIP has its own charm in the form of integration with ports so that it can reduce land route logistics costs. KIP will have an impact on land use and improvement of the road network that occurs around the area. Land use in KIP needs to be monitored so as not to cause problems due to changes in land use in the form of a physical environment. Therefore, Green Open Space (RTH) is needed to reduce the physical impact of the environment and can also improve the comfort of the community around KIP. This study intends to analyze the growth of Green Open Spaces (RTH) as a supporter of the KIP environment at the stage of land clearing and development. The results showed changes in land use occurred from the original water body class by $72 \%$ to $68 \%$ because it turned into open land. This is due to KIP preparing land for industrial use and not yet doing much development. Based on this, land-use changes cause an increase in Land Surface Temperature (LST) in the KIP, but the RTH does not increase. RTH needs to be improved to provide comfort in KIP locations. This research is expected to provide benefits for local governments in making policies for the KIP.

Keywords : Kendal Industrial Park, Land Use, Green Open Space

\begin{abstract}
Abstrak
Kawasan Industri di Indonesia mengalami peningkatan di setiap provinsi khususnya di Provinsi Jawa Tengah karena berdampak positif terhadap kesejahteraan, tingkat ekonomi dan dapat membuka lapangan kerja. Kendal Industrial Park (KIP) merupakan salah satu Kawasan Industri di Jawa Tengah yang sedang mengalami pertumbuhan dan diharapkan dapat menarik investor untuk masuk. KIP memiliki daya tarik tersendiri berupa integrasi dengan pelabuhan sehingga dapat menekan biaya logistic jalur darat. KIP akan berdampak pada tutupan lahan dan peningkatan jaringan jalan yang terjadi di sekitar kawasan. Tutupan lahan di KIP perlu dimonitor agar tidak menimbulkan masalah akibat perubahan tutupan lahan berupa lingkungan fisik. Oleh karena itu, Ruang Terbuka Hijau (RTH) diperlukan untuk mengurangi dampak fisik lingkungan dan juga dapat meningkatkan kenyamanan masyarakat sekitar KIP. Penelitian ini bermaksud untuk menganalisis pertumbuhan Ruang Terbuka Hijau (RTH) sebagai pendukung lingkungan KIP pada tahap pembukaan dan pengembangan lahan. Hasil penelitian menunjukkan perubahan tutupan lahan terjadi dari kelas badan air semula sebesar $72 \%$ menjadi $68 \%$ karena berubah menjadi lahan terbuka. Hal ini disebabkan KIP menyiapkan lahan untuk keperluan industri dan belum banyak melakukan pembangunan. Berdasarkan hal tersebut, perubahan tutupan lahan menyebabkan peningkatan suhu Permukaan Lahan (SPL) di KIP, namun RTH tidak meningkat. RTH perlu ditingkatkan untuk memberikan kenyamanan di lokasi KIP. Penelitian ini diharapkan dapat memberikan manfaat bagi pemerintah daerah dalam pengambilan kebijakan KIP.
\end{abstract}

Kata kunci : Kendal Industrial Park, Ruang Terbuka Hijau, Tutupan Lahan 


\section{PENDAHULUAN}

Industrial Park di Indonesia pertama kali dikembangkan oleh pemerintah melalui BUMN pada tahun 1970-an sebagai reaksi atas kebutuhan lahan untuk mengembangkan industri (Kwanda, 2000). Seiring dengan berjalannya waktu, Industrial Park di Indonesia mengalami peningkatan di setiap provinsi khususnya di Jawa Tengah karena berdampak positif terhadap kesejahteraan dan kondisi perekonomian serta dapat membuka lapangan kerja. Provinsi Jawa Tengah merupakan salah satu provinsi di Indonesia yang menjadi tujuan utama investor menanamkan modalnya untuk perluasan usaha. Hal ini berdampak positif pada peningkatan taraf ekonomi Indonesia menjadi mandiri secara ekonomi. Salah satu Kawasan Industri di Jawa Tengah yang sedang mengalami pertumbuhan adalah Kendal Industrial Park (KIP) yang diharapkan dapat menarik investasi untuk masuk. Hingga Januari 2018, kawasan terintegrasi diresmikan sejak November 2016, menarik 39 investor dari Indonesia, Singapura, Malaysia, China, dan Jepang (Rafael, 2018).

Berdasarkan Peraturan Presiden Nomor 79 Tahun 2019 tentang Percepatan Pembangunan Ekonomi Kawasan Kendal Semarang - Salatiga Demak - Grobogan, Kawasan Purworejo - Wonosobo - Magelang - Temanggung, dan Kawasan Brebes - Tegal Pemalang, percepatan pembangunan ekonomi perlu dilakukan Langkah-langkah strategis dan terintegrasi yang memiliki arah pembangunan yang merata, tearah, fukus, terukur dan stategi yang tepat. Percepatan pembangunan diharapkan meningkatkan daya saing Kawasan yang berdampak pada pertumbuhan investasi dan peningkatan perekonomian nasional yang terintegrasi dan berkelanjutan. Kawasan terintegrasi pertama di Provinsi Jawa Tengah ini ditargetkan menyerap potensi investasi hingga Rp 200 triliun dan tenaga kerja sebanyak 500 ribu orang. (2016, November 15)

Pembangunan Kawasan Industri skala besar akan menghasilkan pembangunan permukiman yang masif sehingga pembangunan permukiman akan menuntut penyediaan infrastruktur dan kebutuhan energi semakin meningkat (Altarans dan Pradoto, 2019). Kawasan tersebut akan berdampak pada perubahan tutupan lahan terutama di sekitar kawasan tersebut karena kebutuhan akan tutupan lahan semakin meningkat. Kendal Industrial Park (KIP) akan berdampak pada tata guna lahan yang terjadi di sekitar kawasan tersebut. Tutupan lahan di KIP perlu dimonitor agar tidak menimbulkan masalah akibat perubahan tutupan lahan berupa lingkungan fisik. Tanah adalah sumber daya dasar untuk kelangsungan hidup dan perkembangan kota-kota (Zhang et al., 2010). Perkembangan KIP perlu dimonitor tentang dampak perubahan tutupan lahan dan ketersediaan Ruang Terbuka Hijau (RTH) untuk memberikan kenyamanan di Kawasan Industri. Berdasarkan data Luas RTH (Ruang Terbuka Hijau) dan Makam yang dikelola Dinas Lingkungan Hidup Kabupaten Kendal Tahun 2017, total luas RTH Kabupaten Kendal sebesar $196,731 \mathrm{~m}^{2}$. Luas RTH Kabupaten Kendal diharapkan tidak berubah signifikan dengan adanya KIP.

Dengan berkembangnya teknologi penginderaan jauh, peta tutupan lahan yang berasal dari citra satelit telah menjadi dasar analisis perubahan tutupan lahan, sedangkan Sistem Informasi Geografis (SIG) memungkinkan untuk mendeteksi dan menganalisis dinamika spasial-temporal pola tutupan lahan. dengan peta-peta ini (Lindquist dan Annunzio, 2016). Dalam hal ini peneliti perlu mengkaji pengaruh yang diberikan terhadap perkembangan KIP dan mengkaji ketersediaan Ruang Terbuka Hijau (RTH). Pengembangan Kendal Industrial Park harus mengacu pada Peta Peraturan Tata Ruang agar sesuai dengan perkembangan Kawasan Kendal. Pemantauan dilakukan dengan melihat tutupan lahan sebelum Kendal Industrial Park diresmikan hingga saat ini untuk melihat pengaruh perubahan tutupan lahan terhadap kesesuaian dengan Ruang Terbuka Hijau (RTH) yang tersedia. Prasarana penunjang berupa jalan raya merupakan salah satu jalur transportasi yang mendukung pengembangan Kendal Industrial Park dan dapat meningkatkan aksesibilitas dan mobilitas masyarakat sehingga jangkauan masyarakat menuju Kawasan Industri dapat terpenuhi dengan baik. Namun, 
perkembangan jaringan jalan dalam proses urbanisasi telah mengancam keanekaragaman hayati dengan membagi lanskap menjadi wilayah yang terfragmentasi dan mengurangi konektivitas ekologis (Wang et al., 2009). Ruang Terbuka Hijau (RTH) berdampak positif, salah satunya adalah menurunkan suhu dengan keteduhan dan kesejukan tanaman untuk memberikan kenyamanan umum. RTH memberikan efek peningkatan Suhu Permukaan Tanah (SPL), dapat memberikan kenyamanan di lokasi KIK. Penelitian ini bertujuan untuk menganalisis perkembangan Ruang Terbuka Hijau (RTH) sebagai pendukung dibangunnya Kendal Industrial Park. Penelitian ini diharapkan dapat memberikan manfaat bagi pemerintah daerah dalam pengambilan kebijakan kawasan Kendal Industrial Park.

\section{MATERI DAN METODE}

Lokasi penelitian berada di Kendal Industrial Park yang terletak di Kabupaten Kendal, Jawa Tengah, Indonesia. Kendal Industrial Park (KIP) dikembangkan bersama oleh PT Jababeka Tbk dan Sembcorp Development Ltd. KIP merupakan kawasan industri terintegrasi dengan luas 2.700 hektar. KIP dirancang sebagai industri kawan berstandar internasional. KIP memiliki lokasi strategis sekitar $21 \mathrm{~km}$ dari Kota Semarang yang merupakan lbukota Provinsi Jawa Tengah, $20 \mathrm{~km}$ dari Bandara Internasional Ahmad Yani, dan $25 \mathrm{~km}$ dari Pelabuhan Tanjung Emas. KIP akan dilengkapi dengan infrastruktur berstandar internasional dengan fasilitas pendukung yang dilengkapi dengan kavling siap pakai untuk pabrik mandiri, pabrik siap pakai, kelistrikan yang andal, pengelolaan udara dan air limbah, perumahan eksekutif dengan fasilitas lengkap. Areal KIP dapat dilihat pada Gambar 1.

Data primer dan sekunder diadaptasi dalam penelitian untuk mendeteksi secara efisien bagaimana suhu permukaan tanah (LST) dipengaruhi oleh perubahan tutupan lahan dan ketersediaan Ruang Terbuka Hijau (RTH). Pengumpulan data dilakukan melalui observasi lapangan dan data instansi pemerintah, serta mengunduh data citra satelit. Observasi lapangan memperoleh data koordinat sampel tutupan lahan, RTH dan LST dilakukan untuk uji interpretasi hasil pengolahan data. Uji interpretasi dilakukan untuk melihat ketelitian hasil klasifikasi yang telah dilakukan terhadap kondisi sebenarnya di lapangan. Penelitian ini menggunakan citra satelit multispektral Landsat 5 tahun 2009, citra satelit Landsat 8 tahun 2019, citra satelit Worldview tahun 2010, dan citra satelit SPOT-6 tahun 2019.

Tutupan lahan merupakan salah satu aspek kunci yang sangat mendukung pembangunan sosial ekonomi manusia (Liu, 2018). Sejak era industri, tutupan lahan dan perubahan tutupan lahan telah berperan penting dalam berkontribusi terhadap perubahan iklim regional dan global dengan mendorong daur ulang energi dan pertukaran material di permukaan tanah (Foley et al., 2005). Transformasi aktivitas manusia, pada gilirannya, memberikan dampak lebih lanjut pada perubahan tutupan lahan dan pembuatan kebijakan terkait. Meskipun banyak manfaat yang berasal dari urbanisasi, dunia yang mengalami urbanisasi yang cepat menghadapi kelangkaan sumber daya yang semakin intensif dan degradasi lingkungan (Liu et al., 2017). Oleh karena itu, perkembangan industri perlu diawasi dengan perubahan tata guna lahan untuk menghindari kerusakan lingkungan. Salah satu kerusakan lingkungan tersebut adalah meningkatnya suhu permukaan di kawasan industri yang menyebabkan menurunnya kenyamanan beraktifitas. Tutupan lahan dalam bentuk lahan maju yang semakin meningkat, harus diimbangi dengan Ruang Terbuka Hijau (RTH) yang memadai. Pemantauan tutupan lahan menggunakan klasifikasi citra satelit agar lebih efisien. Klasifikasi tutupan lahan dilakukan secara otomatis menggunakan klasifikasi terbimbing pada citra Landsat. Perubahan tata guna lahan juga dapat dilihat pada pola perubahan perencanaan pembangunan ke depan.

RTH adalah kawasan hijau yang dibangun untuk memberikan manfaat yang penting bagi kesehatan dan kesejahteraan sepanjang hidup dan berkontribusi pada keberlanjutan suatu kawasan (Villanueva et al., 2015). Keberadaan taman-taman kecil yang tersebar di kawasan perkotaan penting 
untuk membentuk ruang dan habitat (Cunningham dan Cunningham, 2008). RTH merupakan elemen penting suatu daerah untuk membentuk jaringan hijau karena dapat memberikan manfaat bagi kesehatan, kesejahteraan, dan kenyamanan. Oleh karena itu, setiap daerah membutuhkan Ruang Terbuka Hijau (RTH S) untuk menjaga kualitas lingkungan. Namun perubahan tata guna lahan dapat menyebabkan berkurangnya Ruang Terbuka Hijau (RTH) karena adanya peralihan fungsi lahan menjadi kawasan terbangun. Hal tersebut dapat menurunkan kualitas lingkungan sehingga kenyamanan menjadi berkurang. Pemantauan ketersediaan Ruang Terbuka Hijau (RTH) dilakukan agar masyarakat merasa nyaman untuk hidup dan berkreasi. Pemantauan RTH dapat dilakukan dengan metode penginderaan jauh menggunakan interpretasi dan digitasi on screen pada citra. Pemantauan dilakukan secara berkala agar terlihat bahwa RTH di suatu wilayah mengalami peningkatan atau penurunan di wilayah tersebut. Digitalisasi pada layar dilakukan pada citra resolusi tinggi sehingga mudah untuk menafsirkan citra.

Tutupan lahan merupakan cerminan dari campur tangan manusia yang dapat mempengaruhi LST (Yaghobzadeh dan Akbarpour, 2011). LST memberikan informasi tentang konversi lahan yang dapat menyebabkan peningkatan LST melalui informasi tentang perubahan tutupan lahan dan aktivitas manusia yang dapat mempengaruhi lingkungan (Dousset dan Gourmelon, 2013). Menurut Effendi (2007) suhu permukaan merupakan gambaran energi yang terdapat pada suatu permukaan bumi, dengan satuan derajat $C$ atau K.LST berperan untuk melihat kondisi ekosistem akibat perubahan tutupan lahan. LST dapat dideteksi dengan metode penginderaan jauh dengan menggunakan sensor infra merah termal (Effendy, 2007). Nilai suhu permukaan pada data satelit Landsat diperoleh berdasarkan perhitungan nilai kecerahan suhu (Wiweka, 2014). Estimasi suhu permukaan dapat diperkirakan dengan menggunakan pita termal dengan mengubah DN menjadi radian dan mengubah suhu kecerahan untuk mendapatkan nilai suhu permukaan.

\section{HASIL DAN PEMBAHASAN}

Penelitian ini memperoleh klasifikasi tutupan lahan tahun 2009 dan 2019. Tutupan lahan merupakan hasil pengolahan citra landsat dengan menggunakan klasifikasi terbimbing. Penelitian ini menghasilkan 5 kelas tutupan lahan yaitu lahan berkembang, lahan pertanian, lahan terbuka, lahan hutan, dan perairan. Hasil klasifikasi tutupan lahan tahun 2009 dapat dilihat pada Gambar 2. Pada tahun 2009, hasil klasifikasi tutupan lahan diperoleh berupa wilayah penelitian yang didominasi oleh badan air dan lahan pertanian. Hal ini terjadi karena pada tahun 2009 belum ada pengembangan Kendal Industrial Park (KIP) sehingga masih didominasi oleh badan air dan lahan pertanian.

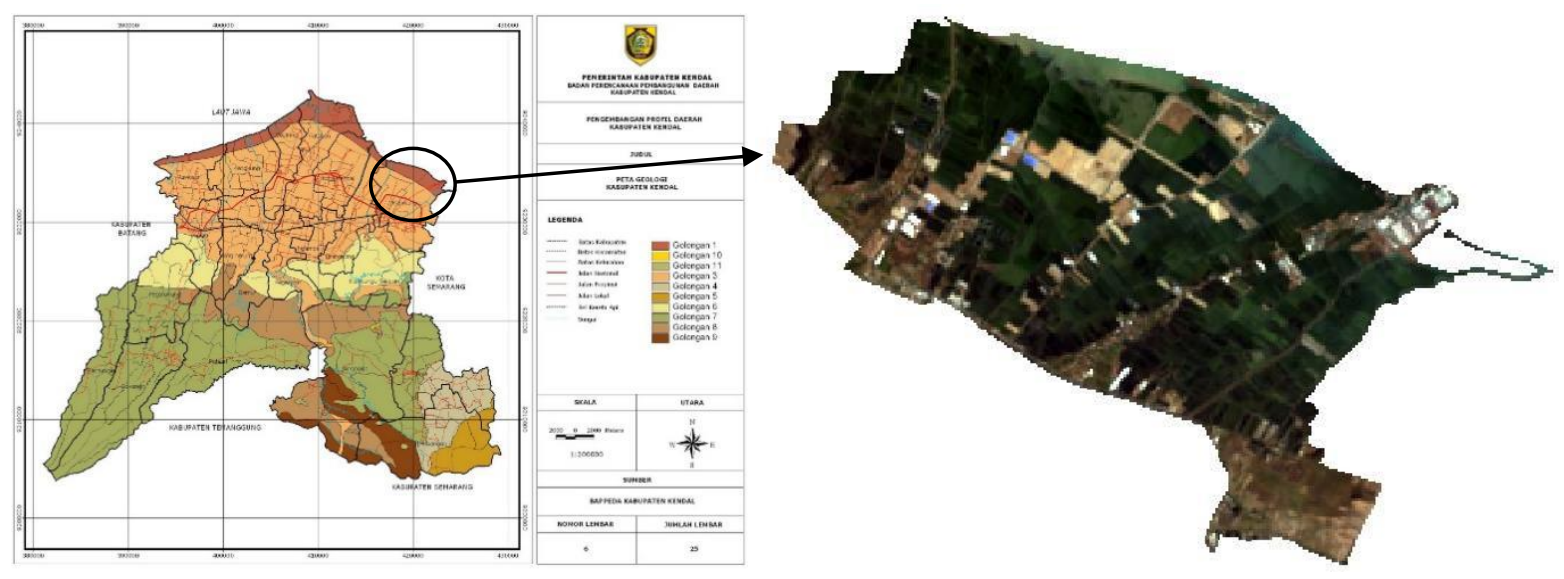

Gambar 1. Area Studi Berlokasi Pada Kendal Industrial Park (KIP) 
Berdasarkan tabel 1 wilayah studi didominasi oleh kelas badan air dengan luas wilayah 844.810 ha atau $72.449 \%$ dari total luas wilayah. Dominasi tersebut terjadi karena pada tahun 2009 sebagian besar wilayah penelitian berupa tambak. Bagaimanapun, mereka dekat dengan laut. Selain itu, pada tahun 2009 masyarakat sekitar memanfaatkan lahan untuk dijadikan lahan pertanian dengan total luas 550.169 ha.

Gambar 3 dapat dilihat dari hasil klasifikasi tutupan lahan tahun 2019. Pada tahun tersebut Kendal Industrial Park (KIP) sudah mulai dikembangkan sehingga tutupan lahan mengalami perubahan. Tutupan lahan pada tahun 2019 mengalami perubahan besar tutupan lahan tambak menjadi lahan terbuka dan kawasan berkembang yang menunjukkan bahwa kawasan industri sedang dibangun. Selain itu, perubahan tutupan lahan juga terjadi pada kawasan badan air menjadi lahan hutan yang terjadi karena di pantai banyak tumbuh tumbuhan bakau sehingga menambah luas lahan hutan di sekitar Kendal Industrial Park. Hasil klasifikasi tutupan lahan 2019 dapat dilihat pada Gambar 3.

Berdasarkan Tabel 2 klasifikasi tutupan lahan tahun 2019 mengalami perubahan besar. Tutupan lahan terbesar adalah badan air seluas 1.745 .484 ha dan tutupan lahan terendah adalah kawasan hutan. Klasifikasi tutupan lahan tahun 2019 dengan klasifikasi tutupan lahan tahun 2015 mengalami banyak perubahan. Perubahan tutupan lahan tertinggi terjadi dari badan air menjadi lahan terbuka dan hutan. Hal ini terjadi karena perubahan tutupan lahan badan air dilakukan dengan reklamasi menjadi lahan terbuka dan lahan hutan. Perubahan tata guna lahan yang telah terjadi belum banyak berubah sehingga tutupan lahan masih didominasi badan air karena pengembangan kawasan industri masih dalam tahap 1 sehingga perubahan lahan belum banyak terjadi.

Bertambahnya kawasan terbangun di Kendal Industrial Park (KIP) menandakan lokasi tersebut siap untuk pengembangan industri dan sudah ada beberapa bangunan pabrik yang dibangun di lokasi tersebut. Sarana penunjang KIP terus dibangun untuk mempercepat pembangunan, salah satunya berupa jalan raya. Perubahan tutupan lahan juga terjadi pada kelas lahan pertanian dari tahun 2009 hingga 2019 terus menurun. Pada kelas lahan hutan terjadi peningkatan karena pada tahun 2019 terjadi peningkatan tumbuhan mangrove di pesisir pantai sehingga membuat luas Kawasan Hutan bertambah. Penilaian akurasi dilakukan untuk melihat tingkat kepercayaan terhadap klasifikasi tutupan lahan. Penilaian akurasi dilakukan berdasarkan hasil survei lapangan dengan melihat kesesuaian hasil klasifikasi dengan hasil survei lapangan. Perhitungan dilakukan dengan menggunakan Matrik Konfusi. Survei lapangan memperoleh 65 titik sampel dan diambil seluruh sampel kelas. Hasil perhitungan dapat dilihat pada Tabel 3.

Tabel 1. Area Tutupan lahan Tahun 2009

\begin{tabular}{lll}
\hline \multirow{2}{*}{ Kelas } & \multicolumn{2}{c}{ Area } \\
\cline { 2 - 3 } & Ha (hektar) & \multicolumn{1}{c}{$\%$} \\
\hline Tubuh Air & $1.844,81$ & 72,44 \\
Kawasan Terbangun & 119,22 & 4,68 \\
Ruang Terbuka & 19,98 & 0,78 \\
Lahan Pertanian & 550,17 & 21,60 \\
Hutan & 12,17 & 0,47 \\
Total & $2.546,35$ & 100 \\
\hline
\end{tabular}

Tabel 2. Klasifikasi Tata Guna Lahan Tahun 2019

\begin{tabular}{lcc}
\hline \multirow{1}{*}{ Kelas } & \multicolumn{2}{c}{ Area } \\
\cline { 2 - 3 } & Ha (hektar) & $\%$ \\
\hline Tubuh Air & $1.745,48$ & 68,55 \\
Kawasan Terbangun & 206,72 & 8,13 \\
Ruang Terbuka & 156,84 & 6,16 \\
Lahan Pertanian & 416,05 & 16,33 \\
Hutan & 21,26 & 0,83 \\
Total & $2.546,35$ & 100 \\
\hline
\end{tabular}

Kendal Industrial Park harus memiliki jumlah RTH yang ideal untuk menunjang kenyamanan kawasan. Namun, RTH tidak hanya bisa dilihat di KIP saja, melainkan di wilayah pendukung sekitarnya. Oleh karena itu, RTH dihitung berdasarkan KIP dan Kecamatan Kaliwungu yang merupakan wilayah sekitar KIP. Kecamatan Kaliwungu memiliki luas 4.609.901 hektar. Berdasarkan data citra satelit, klasifikasi RTH dibedakan menjadi 6 kelas yaitu pekarangan, sawah, 
makam, taman, batas jalan, batas sungai. RTH di lokasi penelitian mengalami penurunan. Perubahan terjadi pada kelas batas jalan dan pekarangan. Perhitungan Tabel 4 Hasil luas RTH dapat dilihat pada Tabel 4.

Hasil pengolahan Suhu Permukaan Tanah/Land Surface Temperature (LST) menghasilkan distribusi suhu permukaan pada setiap piksel citra. Di lokasi penelitian dihasilkan kisaran temperatur permukaan $21^{\circ} \mathrm{C}-30^{\circ} \mathrm{C}$ pada tahun 2009 , dan pada tahun 2019 berkisar antara $24-36^{\circ} \mathrm{C}$. Perubahan LST terlihat semakin meningkat di lokasi penelitian. Berdasarkan hasil pengolahan didapatkan perubahan LST mencapai $6^{\circ} \mathrm{C}$, hal ini disebabkan adanya peningkatan kawasan terbangun sebagai persiapan pembangunan dan pengembangan industri yang telah dilakukan. Gambar 4 menampilkan hasil pengolahan LST tahun 2009 dan 2019.

Berdasarkan Gambar 4, sebaran temperatur permukaan tahun 2009 didominasi oleh warna hijau tua dengan asumsi temperatur permukaan KIK relatif rendah dengan kisaran temperatur $21-24^{\circ} \mathrm{C}$. Hal ini disebabkan pemanfaatan lahan didominasi
Oleh badan air sehingga hasil LST rendah. Pada tahun 2009 juga hanya didapatkan suhu tertinggi pada kisaran suhu $27-30^{\circ} \mathrm{C}$ dengan area yang kecil.

Distribusi temperatur permukaan menghasilkan temperatur terluas pada kelas temperatur $21-24^{\circ} \mathrm{C}$ dengan luas area $2.054,933$ ha atau $80,701 \%$ dari temperatur area di Kendal Industrial Park. Distribusi temperatur permukaan tertinggi berada pada kelas $27-30^{\circ} \mathrm{C}$ dengan luas 22,666 ha atau $0,890 \%$ dari total luas kawasan industri. Berdasarkan Gambar 4, hasil LST 2019 mengalami perbedaan yang signifikan. Distribusi temperatur didominasi oleh warna hijau muda yang menandakan bahwa temperatur permukaan di industri relatif dingin dengan kisaran temperatur $24-27{ }^{\circ} \mathrm{C}$ dan temperatur tertinggi pada range $33-36^{\circ} \mathrm{C}$.

Hasil LST menghasilkan distribusi temperatur terluas pada kelas temperatur 24$27 \circ \mathrm{C}$ dengan luas $1.375,974$ ha atau $54.037 \%$ dari keseluruhan Kendal Industrial Park. Distribusi temperatur permukaan tertinggi berada pada kelas $33-36^{\circ} \mathrm{C}$ dengan luas 66,119 ha atau 2,597\% dari total luas Kendal

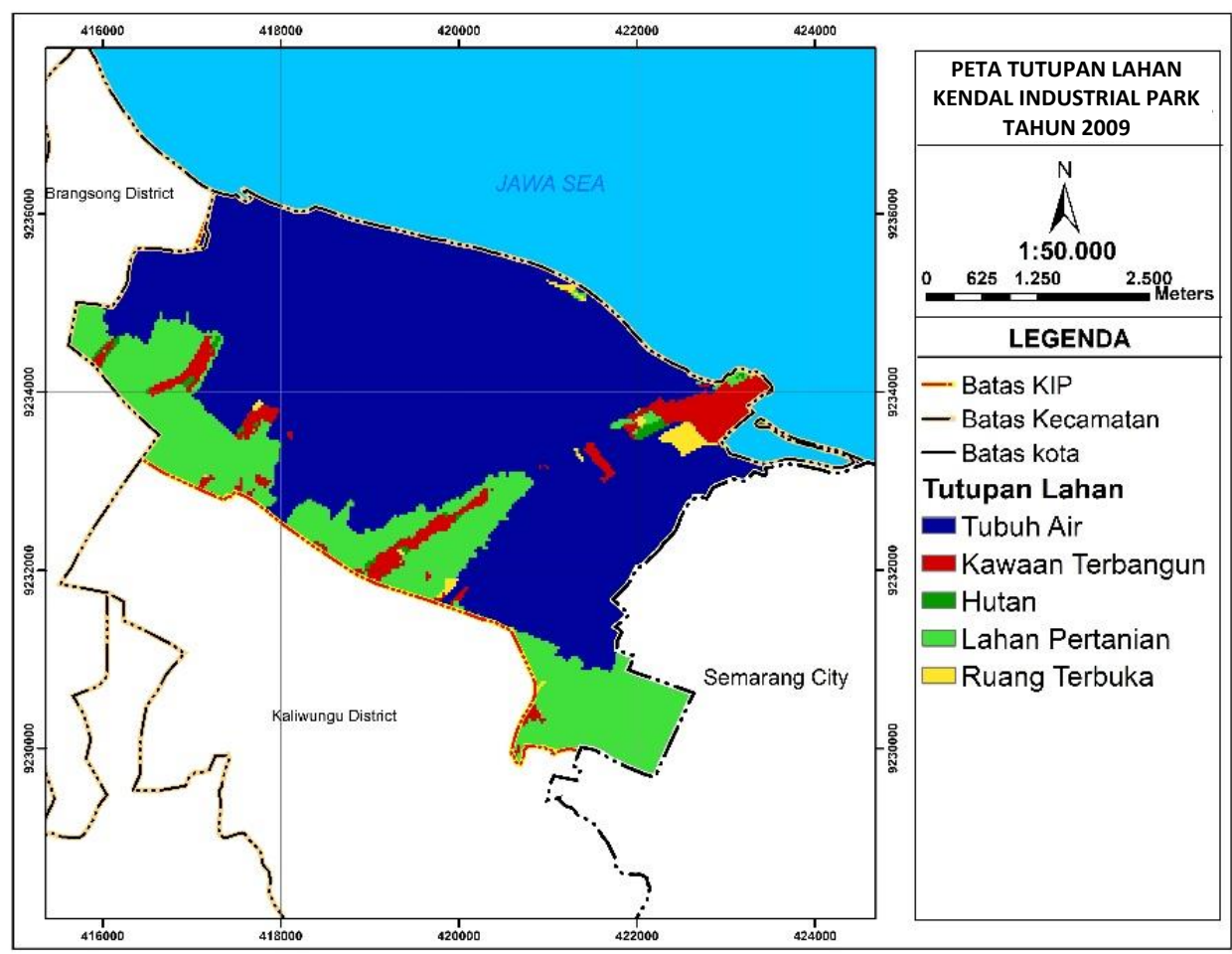

Gambar 2. Hasil Klasifikasi Tutupan lahan Tahun 2009 


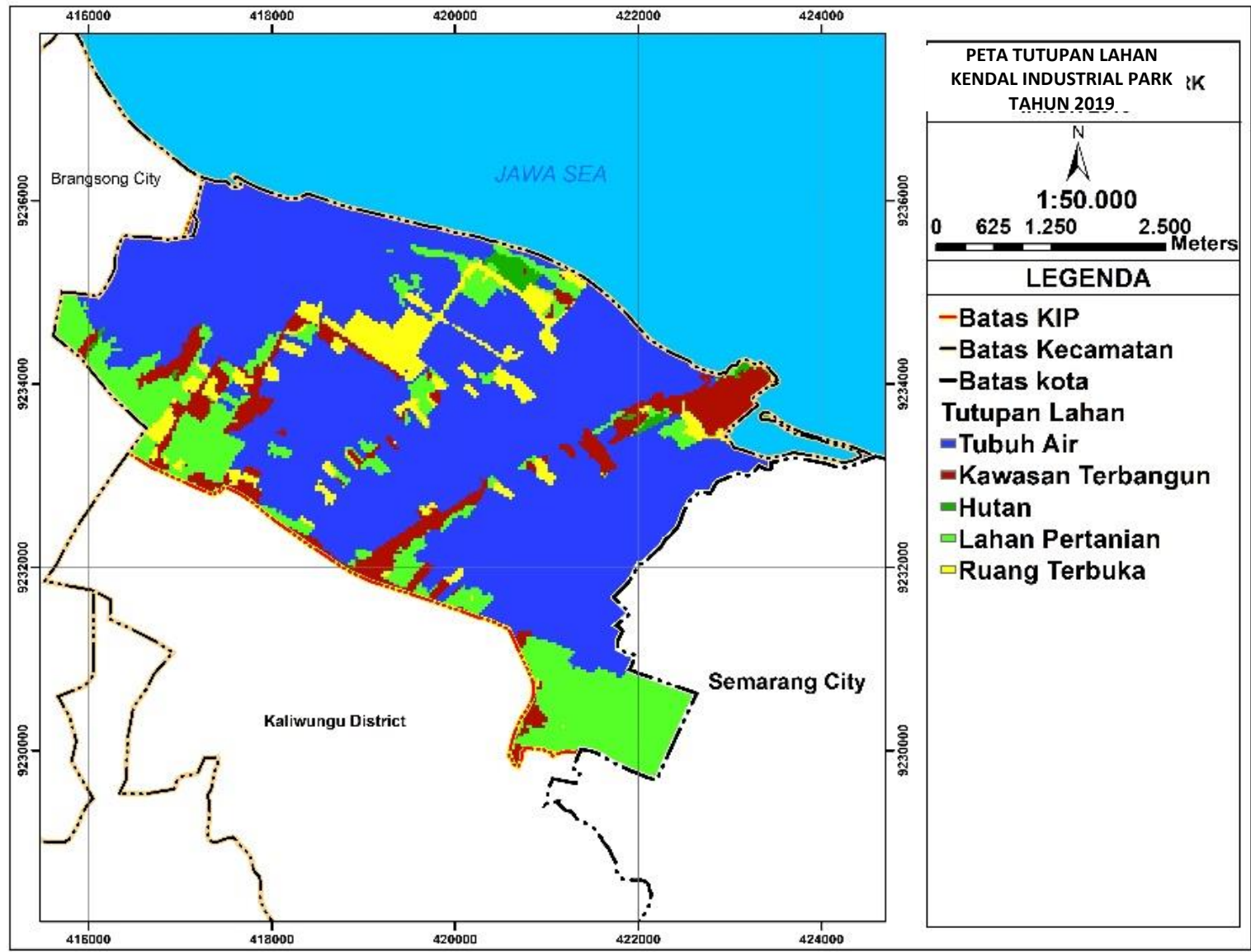

Gambar 3. Hasil Klasifikasi Tutupan Lahan Tahun 2019
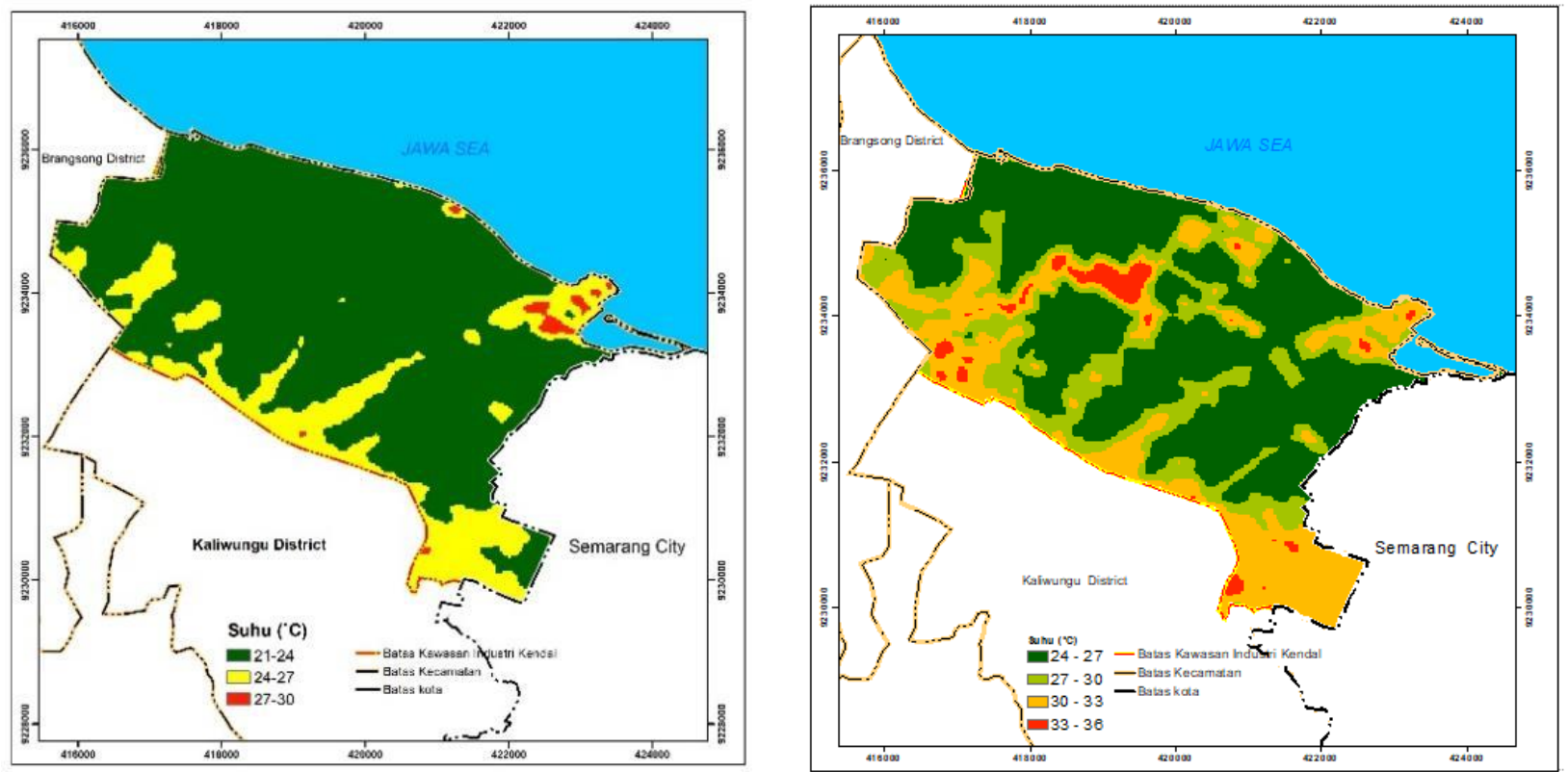

Gambar 4. Hasil Pengolahan LST Tahun 2009 dan 2019 
Tabel 3. Hasil Perhitungan Matrik Konfusi Untuk Tutupan Iahan Tahun 2019

\begin{tabular}{ccccccc}
\hline Kelas & $\begin{array}{c}\text { Tubuh } \\
\text { Air }\end{array}$ & $\begin{array}{c}\text { Kawasan } \\
\text { Terbangun }\end{array}$ & Ruang Terbuka & $\begin{array}{c}\text { Lahan } \\
\text { Pertanian }\end{array}$ & Hutan & Total \\
\hline Tubuh Air & 19 & 0 & 1 & 2 & 0 & 22 \\
Kawasan Terbangun & 1 & 12 & 1 & 0 & 0 & 14 \\
Ruang Terbuka & 1 & 0 & 12 & 0 & 0 & 13 \\
Lahan Pertanian & 0 & 0 & 1 & 11 & 0 & 12 \\
Hutan & 0 & 0 & 0 & 0 & 4 & 4 \\
Total & 21 & 12 & 15 & 13 & 4 & 65 \\
\hline
\end{tabular}

Overall Accuracy 89

Kappa Accuracy $\quad 86$

Tabel 4. Hasil RTH

\begin{tabular}{lcccc}
\hline \multirow{2}{*}{ Kelas } & \multicolumn{3}{c}{ Tahun } \\
\cline { 2 - 5 } & \multicolumn{2}{c}{2010} & $\mathrm{Ha}$ & $\%$ \\
\cline { 2 - 5 } & $\mathrm{Ha}$ & $\%$ & 242,92 & 5,27 \\
\hline Halaman & 248,94 & 5,40 & 3,81 & 0,08 \\
Lapangan & 3,81 & 0,08 & 7,92 & 0,17 \\
Kuburan & 7,92 & 0,17 & 1,5 & 0,03 \\
Taman & 1,5 & 0,03 & 22,59 & 0,49 \\
Pembatas Jalan & 22,61 & 0,49 & 15,17 & 0,33 \\
Pembatas Sungai & 15,17 & 0,33 & 293,916 & 6,377 \\
Total & 299,95 & 6,50 & & \\
\hline
\end{tabular}

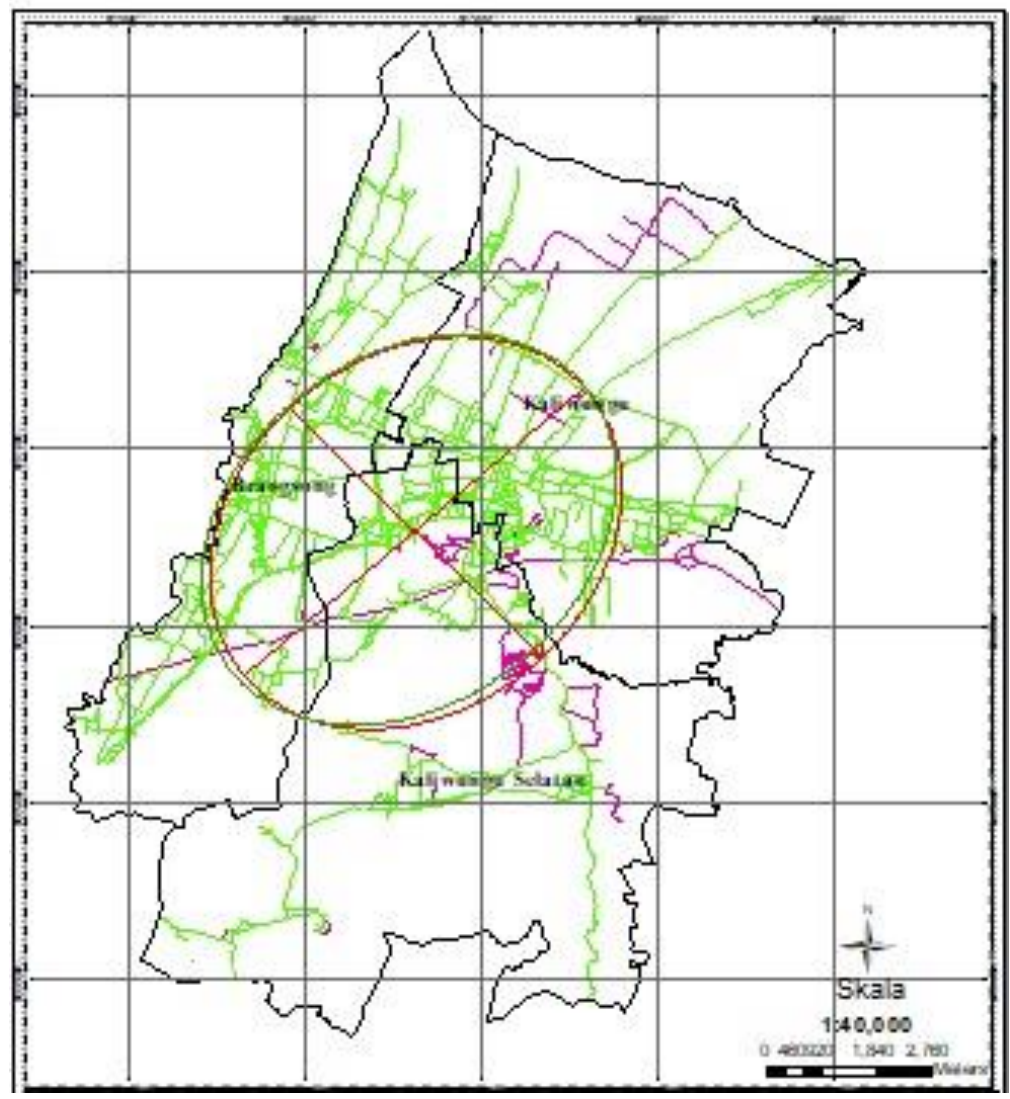

Gambar 5. Pola Pengembangan Jalan 


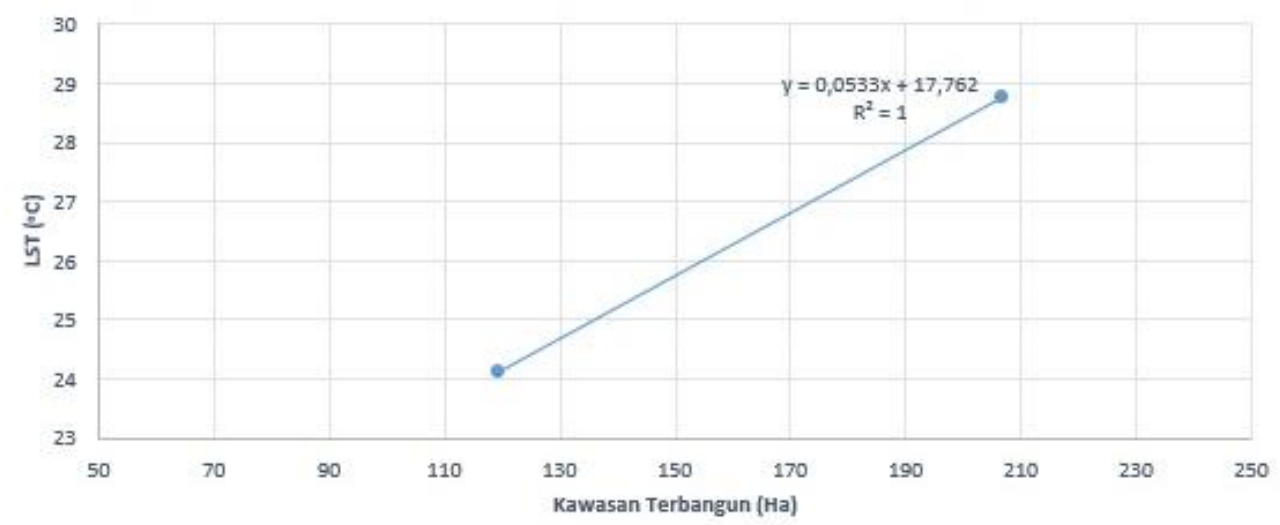

\begin{tabular}{ccc}
\hline \multirow{2}{*}{ Kelas } & \multicolumn{2}{c}{ Tahun 2009 (ha) } \\
\cline { 2 - 3 } & 2009 & 2019 \\
\hline LST & 24,11 & 28,77 \\
Kawasan Terbangun & 119,22 & 206,72 \\
\hline
\end{tabular}

Gambar 6. Korelasi Antara Kawasan Terbangun dan LST

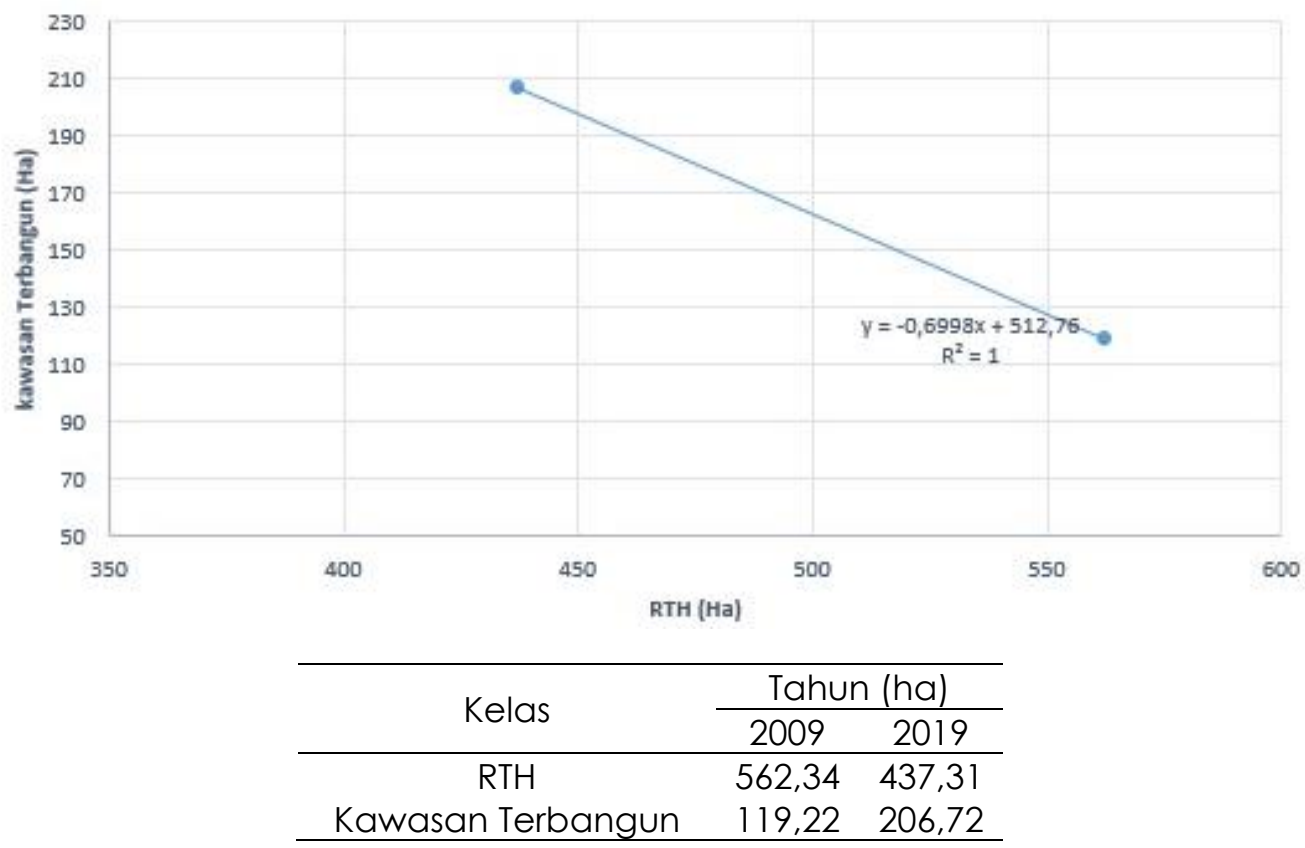

Gambar 7. Korelasi Antara Kawasan Terbangun dan RTH

Industrial Park. Sebaran suhu permukaan pada tahun 2009 dan 2019 terjadi peningkatan suhu permukaan. Hal ini terjadi karena banyaknya perubahan lahan yang menyebabkan peningkatan suhu permukaan dimana banyak terjadi perubahan pada areal tambak yang menjadi kawasan Lahan Terbuka yang nantinya akan dijadikan sebagai Kendal Industrial Park.
Hasil klasifikasi tutupan lahan tahun 2009 - 2019 dapat dilihat pada Gambar 2 dan Gambar 3, dan kualitas klasifikasinya dapat dilihat pada Tabel 3. Penilaian akurasi diperoleh hasil yang baik karena memperoleh akurasi sebesar $89 \%$. Berdasarkan hasil akuisisi, tutupan lahan di KIK mengalami peningkatan pada kelas lahan terbuka dan hutan mangrove yang semula kelas badan air. 
Perubahan tersebut disebabkan KIK melakukan persiapan dengan melakukan pembuatan kolam retensi dan membuat akses jalan. Pola peningkatan akses jalan dapat dilihat pada Gambar 5.

Berdasarkan Gambar 5, dapat disimpulkan bahwa perbaikan jalan mengarah ke KIP. KIP mempengaruhi pertumbuhan jaringan jalan di sekitarnya. Hasil Suhu Permukaan Tanah juga mengalami peningkatan dari tahun 2009 hingga 2019 seperti dapat dilihat pada Gambar 6. Hasil klasifikasi tutupan lahan dan LST dapat disimpulkan bahwa peningkatan tutupan lahan berupa lahan terbuka akan menyebabkan peningkatan LST.

Tabel 5. Luas area LST pada Tahun 2009

\begin{tabular}{ccc}
\hline LST $(\circ \mathrm{C})$ & \multicolumn{2}{c}{ Area } \\
\cline { 2 - 3 } & $\mathrm{Ha}$ & $\%$ \\
\hline $21-24$ & $2.054,94$ & 80,70 \\
$24-27$ & 468,75 & 18,40 \\
$27-30$ & 22,66 & 0,90 \\
$30-33$ & - & - \\
$33-36$ & - & - \\
Total & $2.546,35$ & 100 \\
\hline
\end{tabular}

Tabel 6. Luas area LST pada Tahun 2019

\begin{tabular}{ccc}
\hline LST $(O \mathrm{C})$ & \multicolumn{2}{c}{ Area } \\
\cline { 2 - 3 } & $\mathrm{Ha}$ & $\%$ \\
\hline $21-24$ & - & - \\
$24-27$ & $1.375,974$ & 54,037 \\
$27-30$ & 554,651 & 21,782 \\
$30-33$ & 549,607 & 21,584 \\
$33-36$ & 66,119 & 2,597 \\
Total & $2.546,351$ & 100 \\
\hline
\end{tabular}

Gambar 6 dapat dilihat bahwa terdapat korelasi positif (berbanding lurus) antara peningkatan tutupan lahan dan LST. Peningkatan luas lahan terbuka dan lahan terbangun memiliki pengaruh yang signifikan terhadap LST. Dalam studi ini kenaikan LST sangat tinggi akibat perubahan tutupan lahan berupa badan air menjadi lahan terbuka karena KIP sedang mempersiapkan lahan untuk pengembangan industri di wilayah tersebut. Dalam tahap persiapan pembukaan lahan, berdampak signifikan terhadap LST. Hal ini perlu diperhatikan agar pengembangan KIP dapat mengurangi peningkatan LST di KIP. RTH perlu ditingkatkan untuk menekan LST di KIP meningkat, namun KIP dan sekitarnya tidak meningkatkan RTH antara rentang tahun 2010 hingga 2019. Hal ini menyebabkan peningkatan LST di KIP.

Berdasarkan Gambar 7, peningkatan tutupan lahan tidak diimbangi dengan peningkatan RTH sehingga terjadi korelasi negatif (berbanding terbalik) antara nilai peningkatan tutupan lahan dengan nilai penurunan RTH. Hal ini perlu dieksplorasi lebih lanjut untuk menyebabkan penurunan LST jika tidak dipengaruhi oleh peningkatan RTH. Hal ini dapat menyebabkan ketidaknyamanan aktivitas di KIP yang tidak terdeteksi dalam penelitian ini.

\section{KESIMPULAN}

Pengembangan KIP dengan RTH di KIP menggunakan data citra satelit. Perkembangan KIP dilihat berdasarkan tutupan lahan di lokasi tersebut. Lahan terbangun pada tahun 2009 memiliki luas sebesar 119,22ha dan mengalami peningkatan di tahun 2019 menjadi 206,72ha. Hal ini disebabkan KIP sudah mulai mengalami pembangunan. Sedangkan, RTH tidak mengalami peningkatan justru mengalami pengurangan akibat pembangun tersebut dengan luas RTH pada tahun 2009 sebesar 562,34ha dan pada tahun 2019 menjadi 437,31 ha. Studi ini menemukan korelasi lemah (negatif) antara RTH dan kawasan terbangun karena pembangunan sedang dilaksanakan oleh pihak KIP. Peningkatan kawasan terbangun menyebabkan RTH menurun karena adanya pembangunan sehingga diharapkan RTH di KIP harus dipikirkan kedepannya agar menajga kenyamanan lingkungan. Hal ini membuat LST di KIP bertambah karena kurangnya RTH. Terdapat korelasi yang kuat (positif) antara tutupan lahan dan LST, peningkatan tutupan lahan dapat menyebabkan peningkatan LST. Ini 
harus menjadi perhatian terkait kenyamanan di KIP. RTH memiliki peran penting dalam menekan kenaikan LST dan dapat mengambil kenyamanan dalam KIP.

\section{UCAPAN TERIMA KASIH}

Ucapan terima kasih kepada pemberi dukungan financial terhadap penelitian ini berdasarkan Dana Hibah RKAT Fakultas Teknik Universitas Diponegoro untuk Tahun Anggaran 2020 dan seluruh anggota KK Penginderaan Jauh dan Fotogrammetri di Departemen Teknik Geodesi, Fakultas Teknik, Universitas Diponegoro.

\section{DAFTAR PUSTAKA}

Altarans, I. \& Pradoto, W. 2019. Urban Compactness Di Wilayah Perkotaan Kendal. Jurnal Pembangunan Wilayah dan Kota, 14(4):281-293. doi : 10.14710/ pwk.v14i4.17822

Cunningham, W.P. \& Cunningham, M.A. 2008. Environmental Science A Global Concern Tenth Edition (New York: Mc Graw Hill Higher Edition)

Dousset, B. \& Gourmelon, F. 2003. Satellite multi-sensor data analysis of urban surface temperatures and land cover. Journal of Photogrammetry and Remote Sensing, 58:43-54

Effendy, S. 2007. Keterkaitan Ruang Terbuka Hijau Dengan Urban Heat Island Wilayah Jabotabek. (Disertasi). Departemen Meteorologi dan Geofisika IPB, Bogor.

Foley, J.A., Defries, R., Asner, G.P., Barford, C., Bonan, G., Carpenter, S.R., Chapin, F.S., Coe, M.T., Daily, G.C., Gibbs, H.K. \& Helkowski, J.H. 2005. Global consequences of land use. Science, 309:570-574.

Kwanda, T. 2000, Pengembangan Kawasan Industri di Indonesia. Journal of Architecture and Built Environtment, 28(1): doi : 10.9744/dimensi.28.1.
Lindquist, E. \& D'Annunzio, R. 2016. Assessing Global Forest Land-Use Change by Object-Based Image. Remote Sensing Analysis, 8(8):678p.

Liu, Y. 2018. Introduction to land use and rural sustainability in China. Land Use Policy, 74:1-4. doi : 10.1016/j.landusepol.2018. 01.032

Liu, Y.S., Yang, Y.Y., Li, Y.R. \& Li, J.T. 2017. Conversion from rural settlements and arable land under rapid urbanization in Beijing from 1985-2010. Journal of Rural Studies. 51:141-150.

Rafael, E.C., 2018. Pengembangan industri di Jawa Tengah berbasis padat karya dan berorientasi ekspor. https://industri.kontan. co.id/news/pengembanganindustri-dijawa-tengah-berbasis-padat-karya-danberorientasi-ekspor. Diakses tanggal 22 Maret 2019 Jam 20.00 WIB.

Villanueva, K., Badland, H., Hooper, P., Koohsari, M.J., Mavoa, S., Davern, M., Roberts, R., Goldfeld, S. \& Giles-Corti, B. 2015. Applied Geography. 57;112-119.

Wang, Y., Meng, D., Zhu, Y. \& Zhang, F. 2009. Impacts of regional urbanization development on plant diversity within boundary of built-up areas of different settlement categories in Jinzhong Basin, China. Landscape and Urban Planning, 91:212-218

Wiweka. 2014. Pola Suhu Permukaan Dan Udara Menggunakan Citra Satelit Landsat Multitemporal. Jurnal Ecolab, 8(1):11-22. doi : 10.20886/jklh.2014.8.1.11-22

Yaghobzadeh, M. \& Akbarpour, A. 2011. The effect of satellite image classification algorithm based on curve number runoff and maximum food discharge using GIS and RS. Geography and Development, 9(22):5-22

Zhang, S., Zhang, B., Zhang, L., LU, C. \& Cheng, $X$. 2010. Spatiotemporal evolution of urban land use in modern urbanization of China. Chinese Geographical Science, 20:132-138. 